\title{
Determination of state of electrical equipment by spectra of wattmetrograms
}

\author{
Valeriy Manakhov ${ }^{1, *}$, and Alexey Tsvetkov ${ }^{1}$ \\ ${ }^{1}$ Kazan State Power Engineering University, Kazan, Russia
}

\begin{abstract}
The purpose of the work is to develop a method of diagnostics and control of oil production equipment to improve energy efficiency and optimize operation modes, through the use of a wattmeter program and its spectrum. The method of diagnostics according to the wattmetrogram is based on obtaining the active power spent by the electric motor for one period of rocking of the rocker. Analysis of the spectrum of wattmetrograms makes it possible to more accurately diagnose defects of this equipment. Thus, control over the spectra of the wattmetrogram is a more accurate and promising method of diagnosing equipment. Materials and methods: In the development of this issue, both domestic and foreign literature was used. The technical data of the control stations and sensors were used on the basis of actual electrical equipment. The prospects and benefits of using diagnostic options weltmetropole: relatively small number of sensors (current and voltage transformers); ability to measure the electric power consumed by the drive; ability to integrate with automated systems of technical and commercial electricity metering; the task is relevant already today, but it is quite promising in the future, due to the rapid development of technologies that allow for digital processing of wattmetrograms; use of these technologies in practice; economic advantages over similar representatives of this segment; service life of more than 20 years; ability to work in a wide temperature range $-40-+60$.
\end{abstract}

\section{Introduction}

One of the leading industries of the Russian Federation is the oil and gas industry. According to experts, this is $48 \%$ of all revenues of the Federal Budget. The cost of the Russian ruble, therefore, and the Russian economy as a whole, largely depend on world oil prices. Most of the oil wells are operated by sucker-rod pumping units (SRPU) (Fig. 1). SRPU drives are equipped with jack pump that convert rotary motion of engine shaft into reciprocating motion of rod suspension point. Continuous monitoring and diagnosis of SRPU equipment condition is currently the most important aspect for avoiding the occurrence of emergency situations in wells caused by equipment malfunctions.

The use of the SRPU provides:

- the ability to extract reservoir fluid from units to hundreds of cubic meters per day at acceptable energy costs;

- easy maintenance and repair in the field;

- low influence (in comparison with other methods) on the operation of the SRPU, the chemical and physical properties of the liquid;

- low requirements for the qualification of personnel. Rod downhole pumping units consist of ground and underground equipment (Figure 1).

The ground equipment includes •

- electric motor;

- gear box;
- crank mechanism

- load balancer;

- square shaft and bearings;

- balancer head;

- base of the rocking machine (SC);

- cable;

- traverses;

- oil seal device;

- the tee.

The underground equipment includes:

- pump and compressor pipes (tubing);

- rods;

- pump working cylinder;

- pump plunger (piston).

During operation, the energy from the engine is transferred via a gear to the crank mechanism that converts rotational motion of the output shaft of the reducer via the balancer head, the reciprocating movement of the column of rods. The plunger, which is connected to the column, also performs a reciprocating motion.

When the plunger moves up, the pressure of the liquid closes the discharge valve located above the plunger, the liquid moves up along the column of pump and compressor pipes - it is pumped out. At this time, the suction inlet valve is open and the volume of the pump cylinder under the plunger is filled with liquid.

When the plunger moves down, under the pressure of the liquid column, the suction valve closes, and the

\footnotetext{
*Corresponding author: Valeriy_Manakhov@mail.ru
} 
discharge valve opens and liquid flows into the overplunger space of the cylinder.

The liquid raised to the surface enters the field collector through the side outlet of the wellhead gland.

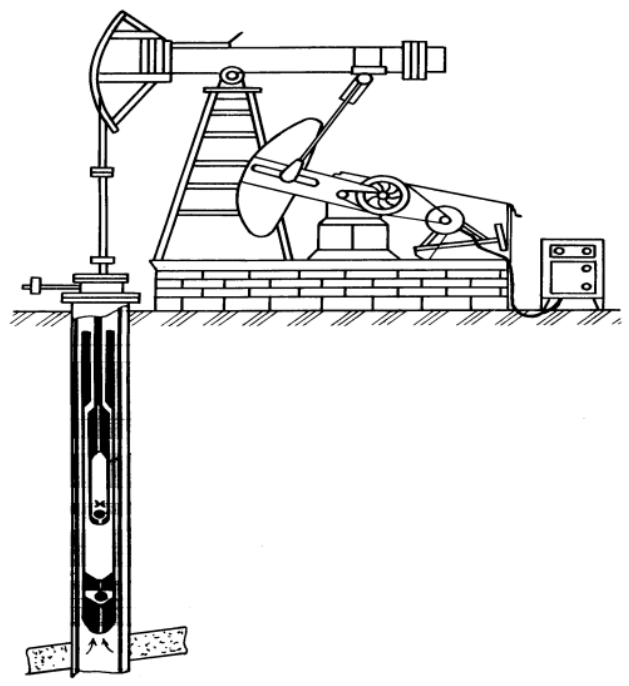

Fig. 1. Sucker-rod pumping units.

Monitoring of SRPU equipment statuses by wattmetrogram.

The main task of SRPU diagnostics is to determine the technical condition of the equipment and its components, as well as to identify malfunctions for the purpose of rational planning of maintenance, operation and repair to ensure the required reliability. Wattmetering is one of the methods of diagnosing SRPU, which allows to identify the main malfunctions of the mechanical part of the equipment of the bellcrank. The wattmetrogram is the dependence of instantaneous values of active power consumed by the SRPU electric motor on time depending on the crank rotation angle: $\mathrm{P}(\mathrm{t}), \mathrm{P}(\phi)$, where $\mathrm{t}$ is the time during one period T of rocking of the plant balancer, $\phi$ - is the crank rotation angle. (Fig. 2).

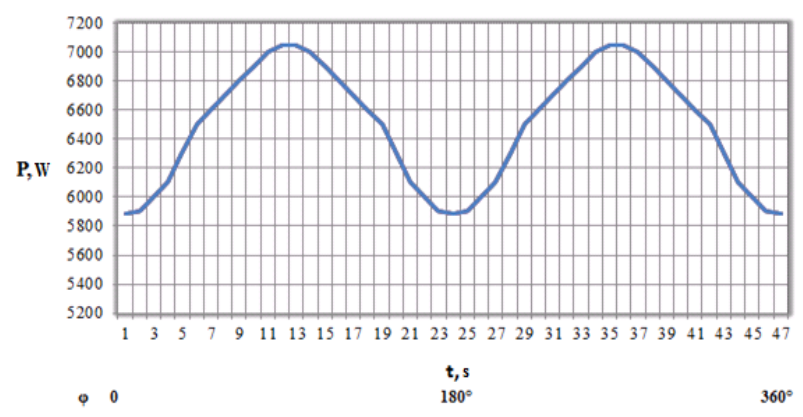

Fig. 2. Wattmetrogram at normal operation of the unit.

As a diagnostic tool, wattmetering began to be used earlier than dynamometering. In the USSR, scientists, Doctor of Technical Sciences Krichke Vladimir Oskarovich developed electronic analog devices for processing wattmetrograms in 1975 . However, the widespread use of this diagnostic method was prevented by the low calculated power of the controllers.
Wattmetering is one of the leading in terms of information content by the method of monitoring and diagnostics of the equipment of SRPU. The ease of measuring the amount of power consumed by the electric motor is an advantage of wattmetering, for this it is necessary to install only voltage and current measuring transformers at three phases of the electric motor, there is also the possibility of keeping records of the electricity consumed by the SRPU [2].

To analyse wattmetrograms, you will need an array of data consisting of instantaneous values of current and voltage, followed by their multiplication in one period of swing. Also, active, reactive and full power, power factor, current and voltage values can be obtained from these arrays.

An array is an ordered set of elements, each of which stores one value, the array has a constant length and stores units of data of the same type, and numbers (points) act as indexes.

Wattmetering makes it possible to detect the following failures of the electric motor: current overload, phase skew, deviation of the frequency of the supply voltage, etc. Wattmetrogram allows real-time monitoring of such faults as: breakage of rods, defect in mechanical drive, namely beating in reduction gear box, unbalancing of counterweights, defect of both pressure and suction valves, fountain manifestations in boreholes, breaking and slipping of belts, faults of polished rod and plunger [1].

Wattmetering module, current and voltage sensors.

The electronic wattmetering module is designed to monitor and diagnose an oil well equipped with a sucker-rod well pump as part of a hardware and software complex.

When operating as part of this complex, the module provides the solution of the following tasks: operational detection of emergency situations and non-conformity of equipment operation modes, automation of the bellcrank, optimization of equipment operation modes, receipt of operational information about the state of the object on the operator's console or via the telemechanics network.

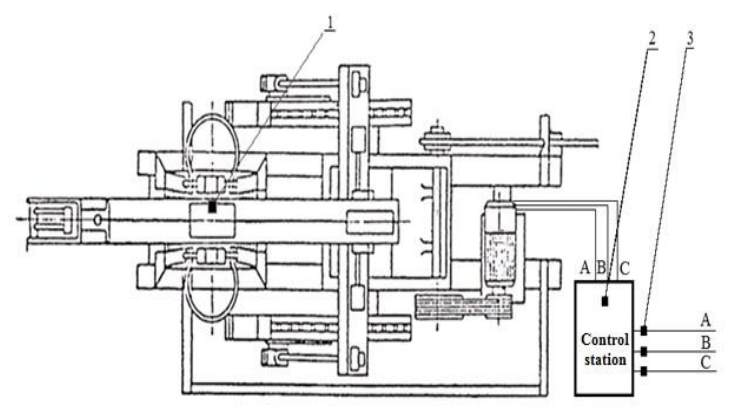

Fig. 3. Location of sensors installation on the jack pump (top view).

Figure 3 shows the locations of the sensors, where 1 is the bottom dead center sensor for determining the period of operation of the bell-crank, 2 is the wattmetering module, 3 are the current and voltage sensors. 
This method uses current and voltage sensors based on the Hall Effect; they are used to measure AC and DC current or voltage. The main element of these sensors is a thin rectangular semiconductor plate with four electrodes. One pair of contacts is connected to short sides of plate to supply control current. These contacts are called current electrodes. The other pair of contacts is located in the middle of the long sides and is intended for voltage removal. They are called Hall or output electrodes. If the plate penetrates the magnetic flux, then under the action of the Lorentz force, the movable charge carriers form a control current, which leads to a change in the number of charge carriers at the ends of the plate. So there's a Hall voltage on the output electrodes.

The wattmetering module is designed to measure currents, voltages, power consumption and electricity by three phases of electric motors of bell-cranks, as well as for a periodic set of wattmetrograms. It is installed in the well control cabinet or other cabinet in accordance with the design documentation.

The module performs the following functions:

- periodic measurement of instantaneous (during the period of measured alternating current) values of voltages and currents by three phases of the measured network,

- calculation of period (frequency) of measured alternating current by phase $\mathrm{A}$,

- calculation of voltage and current values acting for the period by three phases,

- calculation of total power, active power and factor three-phase power,

- calculation of phase shift between phase voltages $\mathrm{A}$ and $\mathrm{B}, \mathrm{A}$ and $\mathrm{C}$,

- calculation and periodic accumulation of electric energy in three phases,

- periodic (with a given period) updating of arrays of active values of currents, voltages and active power in three phases.

During operation, the module cyclically measures the values of current and voltage supplied to the input terminals of the connector. According to measured instantaneous values of currents and voltages of three phases, the microcontroller of the module calculates the declared parameters of power consumed by the equipment.

In order for the module to operate, the input voltage amplitude of phase A must be greater than 20 volts AC. Otherwise, microcontroller calculations cannot be performed and all results will be missing or may be incorrect.

Calculation of claimed parameters for each phase is carried out independently (except for voltage phase shifts between phases A and B, A and C).

Typical faults of the SRPU.

Let us consider typical malfunctions of WCS detected using wattmetrograms. Red vertical elevations show the so-called rolling period of the oil bell-crank or the lower position of the polished rod.
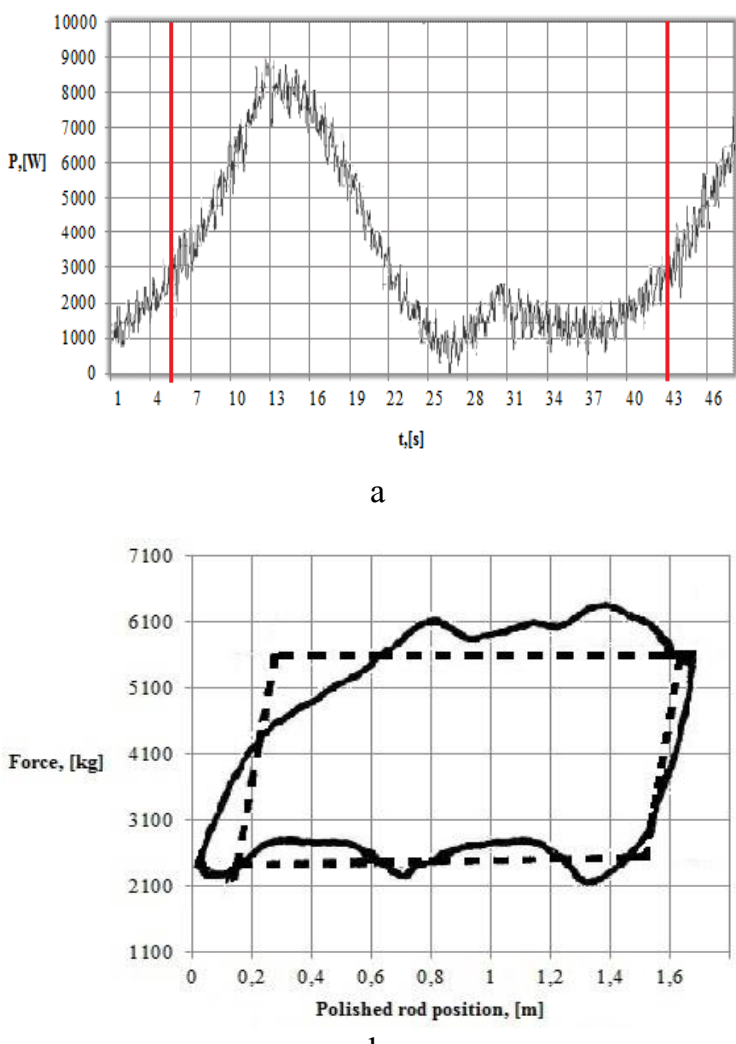

b

Fig. 4. Pressure valve defect a) wattmetrogram b) dynamogram.
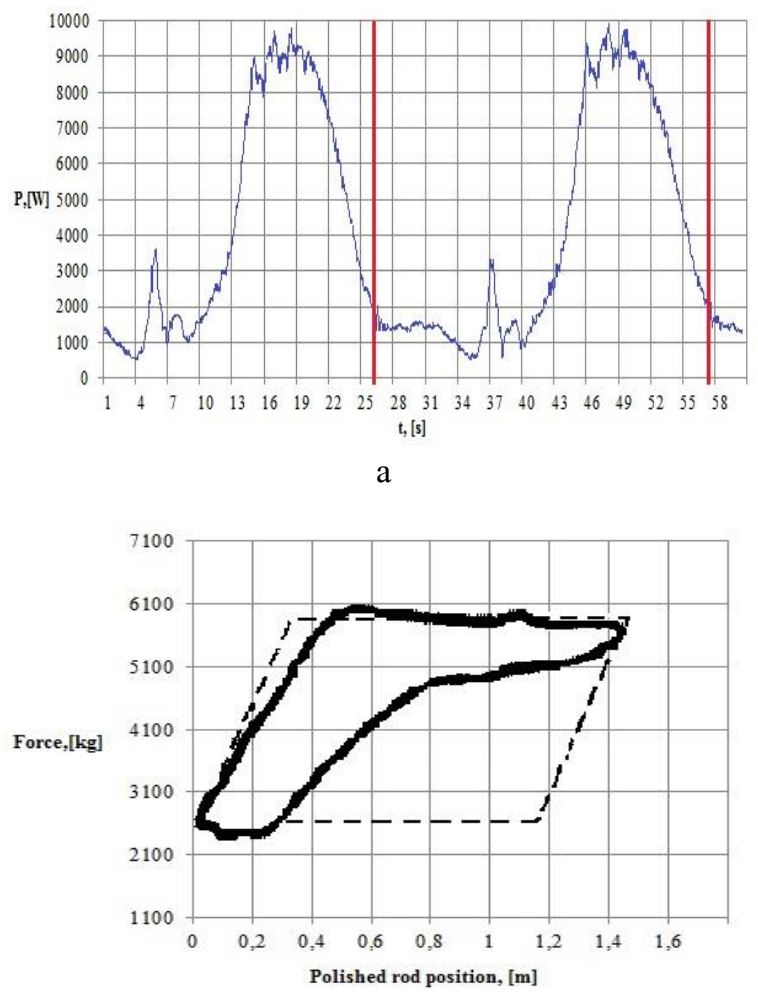

$\mathrm{b}$

Fig. 5. Presence of gas in well a) wattmetrogram b) dynamogram. 


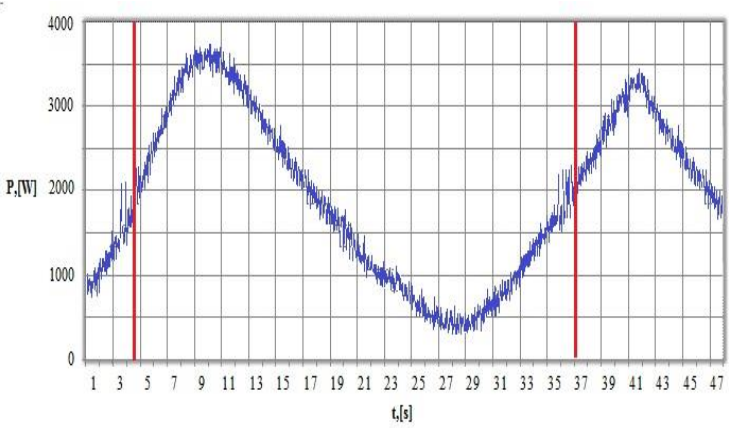

a

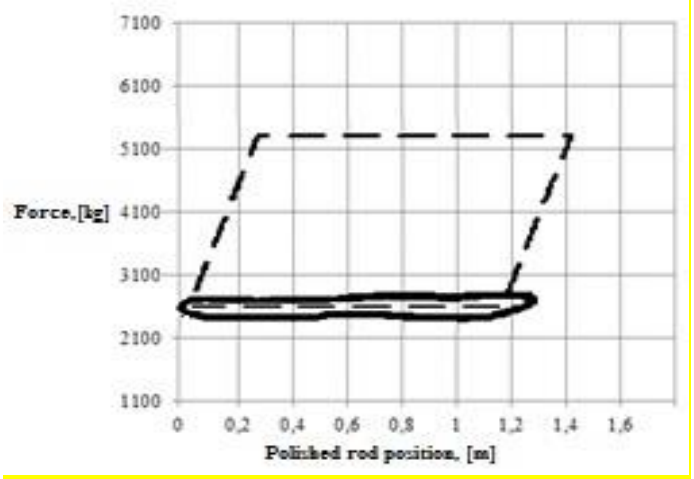

b

Fig. 6. Breakage of rods a) wattmetrogram b) dynamogram.

Figures $4 \ldots 6$ show typical failures of jack pump and their manifestations on wattmetrograms and dynamograms. As can be seen from the figures, the failures of the jack pump have a clear reflection on the form of the wattmetrogram, which is manifested, in particular, by the change in the area ratio of the two halves of the wattmetrogram.

\section{Results and Discussion}

To determine the state of jack pump, studies were carried out at the current SRPU to analyze the technical state of oil equipment by wattmetering and dynamometering. Based on the obtained data, a wattmetrogram was built in the software complex for solving the problems of technical calculations "MATLAB" (Fig. 7).

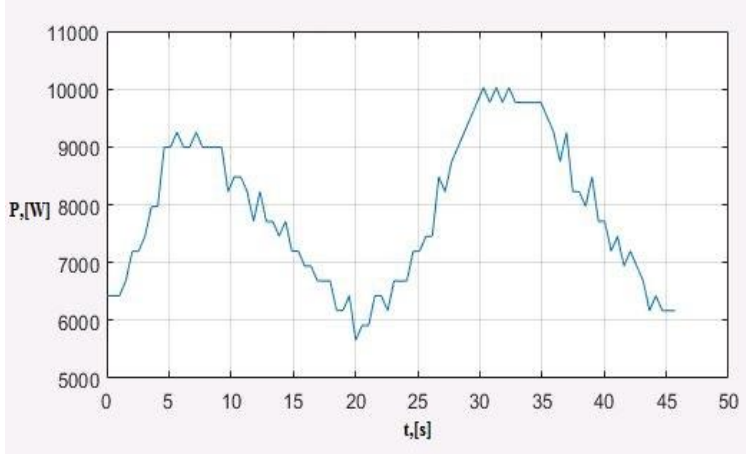

Fig. 7. Wattmetrogram with the current SRPU.
The dynamogram corresponding to this wattmetrogram is also installed (Fig. 8).

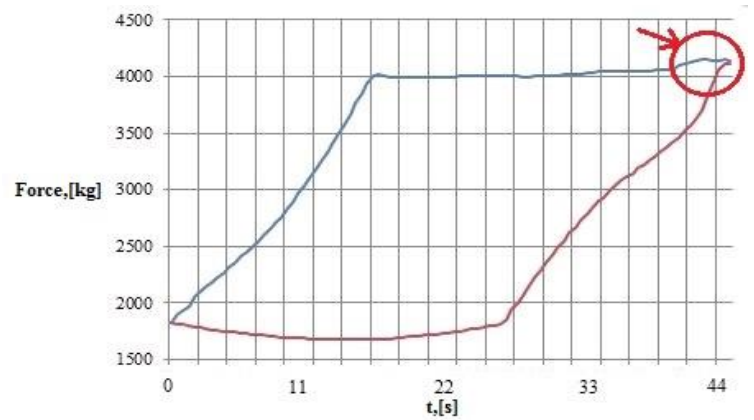

Fig. 8. Dynamogram from the effective SRPU.

On the constructed dinomogram, we see an implicit defect in the small impacts of the plunger on the upper limiting nut of the insertion pump (Fig. 8). To identify this defect on the wattmetrogram, a number of transformations and calculations must be carried out (figures 9... 11).

Wattmeter processing starts with a smooth plot. To build it, we will use the Chebyshev low-pass filter (moving average filter) in the MATLAB software complex and build a smoothed wattmetrogram.

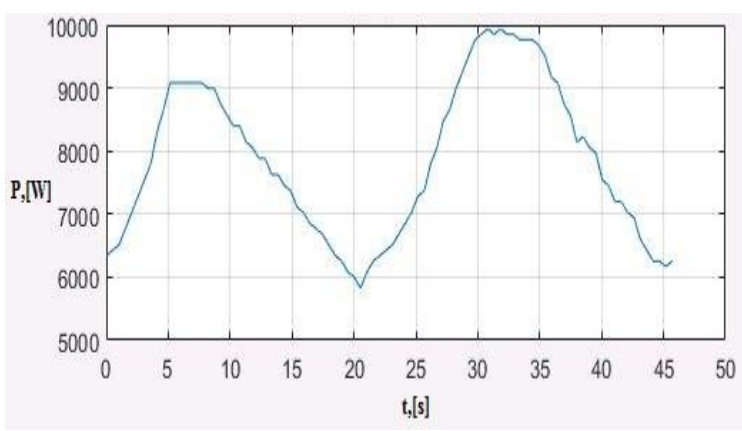

Fig. 9. Smoothed plot of the wattmetrogram.

Next, the wattmetrogram array is run through the filter, cutting off the constant (low-frequency) component to see vibrations, shocks, and noises. The high-frequency component is located relative to the zero axis, so it has negative values. This allows you to see the presence of impacts, jams at certain points in time, to detect defects in the bell-crank and reduction gear (in gears).

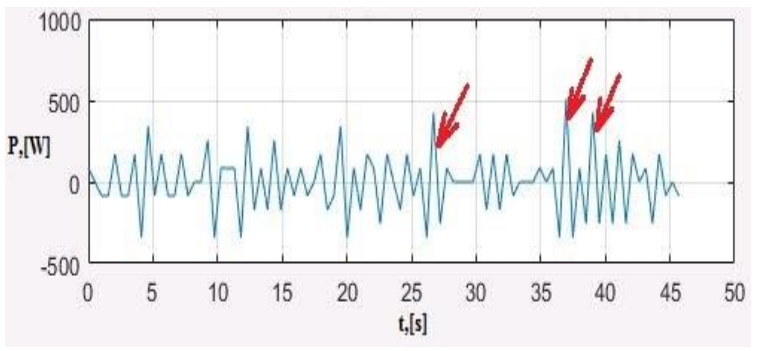

Fig. 10. Wattmetrogram array after filtering.

Then we build the spectrum of this wattmetrogram, passing it through a high-frequency filter, thereby 
removing values with a high frequency from the resulting spectrum.

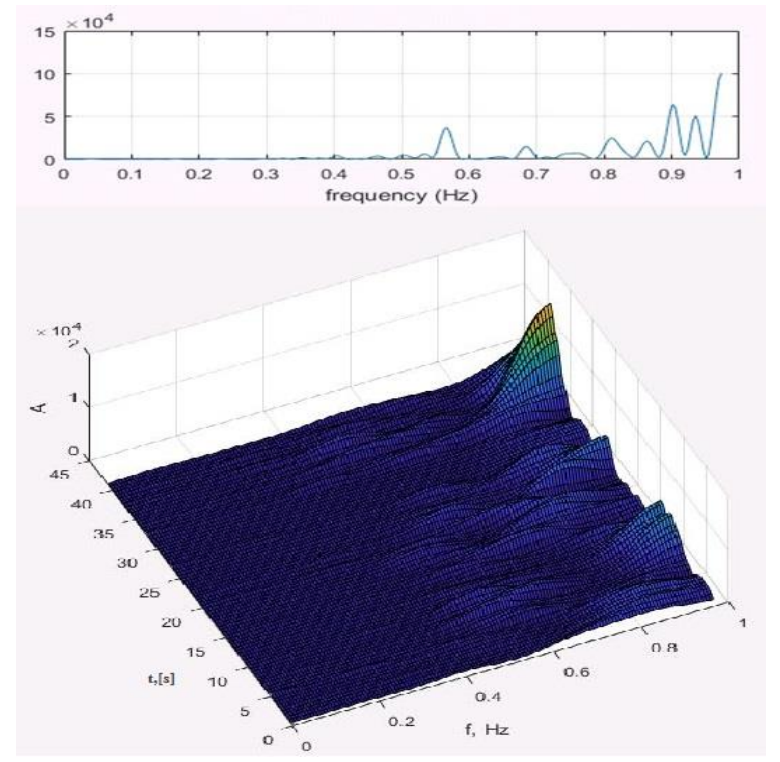

Fig. 11. Frequency spectrum of the signal in two-dimensional and three-dimensional form.

By analysing the array of wattmetrograms and its spectrum (Fig. 10 and Fig. 11), it can be argued that at 26.37 and 39 second there is an excess of the average value of noise energy by 2.5 times and more, which corresponds to shocks with a frequency of $0.8 \ldots 1 \mathrm{~Hz}$. As we can note, at 37 seconds there is the greatest shock, which is also diagnosed using the constructed dynamogram (Fig. 8).

\section{Conclusion}

The wattmetering method historically appeared earlier than the dynamometering method, but was not so developed due to the lack of fast computer calculation, unlike dynamometering, according to which many scientific papers were written.

Building a dynamogram using wattmetering and modern computer equipment will help increase the efficiency of both methods, on the part of wattmetering this is the ease of installation, the minimum number of sensors and a deeper analysis of faults using the spectrum of wattmetrograms, and on the side of dynamometering - this is the development of this topic. Together, the resulting equipment diagnostic method has advantages over other non-destructive diagnostic methods.

\section{References}

1. M.I. Khakimyanov, M.G. Pachin, Monitoring of the state of rod deep-pump installations based on the results of the analysis of wattmetrograms [Electronic resource], Electronic scientific journal "Oil and Gas Business", 5, 26-36 (2011) Available
http://www.ogbus.ru/authors/Hakimyanov/Hakim yanov_7.pdf

2. M.I. Khakimyanov, Improving energy efficiency and optimizing the operating modes of electric drives in the oil industry: dis. doc. of technical sciences: 05.09.03: defended 01.03.19, Moscow, 355 (2018)

3. I.N. Isachenko, E.I. Goldstein, G.P. Nalimov, Methods for controlling the balance of the rocking machine based on the measurement of electrical parameters, Oil industry, 1, 60-61 (2002)

4. G.S. Abramov, A.V. Barychev, V.V. Churakov, Wattmetric methods of monitoring the operation of wells, Neftegaz., 3, 87-89 (2003)

5. V.O. Krichke, Automatic analyzer of the operation of the deep-pump unit, Automation and telemechanics in the oil industry, 12, 10-14 (1975)

6. V.O. Krichke, Analysis of the operation of rocking machines with automatic devices, Automation and telemechanics in the oil industry, 5, 23-25 (1976)

7. V.N. Ivanovsky, Energy of oil production: the main directions of optimization of energy consumption, Engineering practice, 6, 18-26 (2011)

8. M.I. Khakimyanov, Processing batterram sucker rod pump installations, Of the Certificate of state registration of a computer program, $\mathbf{2 0 1 2 6 1 6 1 3 0}$ (4 July 2012)

9. S.V. Porshnev, MATLAB, Fundamentals of operation and programming, Textbook (M.: Binom. Knowledge Lab, 320, 2006) ISBN: 59518-0137-0

10. E.A. Kurbatova, MATLAB, Self-help guide (M.: Williams, 256, 2006) ISBN: 5-8459-0904-X

11. T.I. Petrov, A.R. Safin, I.V. Ivshin, A.N. Tsvetkov, V.Y. Kornilov, The Prospects of Using a Synchronous Machine with Permanent Magnets in the Oil Industry, 2018 14th International Scientific-Technical Conference on Actual Problems of Electronic Instrument Engineering, APEIE 2018, 8546157, 336-338 (2018)

12. A. Kowalczyk, A.J. Witkowski, Groundwater recharge of carbonate aquifers of the SilesianCracow Triassic (southern Poland) under human impact, Environmental Geology, 55 (2), 235-246 (2008) DOI: 10.1007/s00254-007-0999-9

13. D.I. Shishlyannikov, N.V. Chekmasov, M.G. Trifanov, S.L. Ivanov, I.E. Zvonarev, Substantiation of the rational method to control the operating and technical-condition parameters of a heading-and-winning machine for potash mines, Journal of Machinery Manufacture and Reliability, 3, 283-287 (2015) DOI: 10.3103/S105261881503019X 
14. D.I. Shishlyannikov, M.A. Vasilyeva, Operational control and diagnostics of the equipment by the parameters of the electric drive powersupply by the example of deep well pump units, MEACS2016, IOP Conference Series: Materials Science and Engineering, 177, 12-16 (2017) DOI: 10.1088/1757-899X/177/1/012013

15. U. Ryssel, J. Ploennigs, K. Kabitzsch, M. Folie, Generative Design of Hardware-in-the-Loop Models, APGES'07, Salzburg, Austria, 4-11 (2007)

16. D.S. Torgaeva, M.P. Sukhorukov, Y.A. Shinyakov, N.A. Shalyapina, Development of a Sucker Rod Pumping Unit Simulation Model, International Journal of Engineering and Advanced Technology (IJEAT), 9 (1), 4403-4409 (October 2019). 